Iksoo Kwon* and Eunsong Kim

\title{
(Meta-)Ground Viewpoint Space and structurally-framed irony: A case study of the mobile game Liyla and the Shadows of War
}

\author{
https://doi.org/10.1515/cog-2020-0001 \\ Received January 2, 2020; accepted October 31, 2020; \\ published online November 26, 2020
}

\begin{abstract}
Within the framework of Viewpoint Spaces (Dancygier, Barbara. 2012. The language of stories: A cognitive approach. Cambridge: Cambridge University Press), this paper investigates viewpoint interactions in a mobile game's plot to show how the game's structural framing leads to meaning construction, specifically the construal of irony. The notion of (meta-)Ground Viewpoint Space is proposed not only to provide a generalized account of a global mental space where local spaces and viewpoints relate to one another, but also to elucidate how the invoked genrespecific expectation makes a significant meaning contribution to the player's overall construal of the game. This study presents a case study of the mobile game Liyla and the Shadows of War (Abueideh, Rasheed. 2016. Liyla and the Shadows of War) as a viewpoint phenomenon whose construal involves the interaction of multiple viewpoints. The game depicts the consequences of the 2014 Gaza conflict from the perspective of an unnamed Palestinian father struggling to escape the war zone with his daughter Liyla. It deviates from prototypical games in that it is impossible to complete the expected narrative, regardless of the player's skill, although its ostensible goal is to let the protagonists survive and escape to a safer place. The mismatch between the player's goal to clear all the stages, the character's goal to survive, and the developer's goal to convey a message is a source of ironic meaning, and this study focuses on how the network of multiple viewpoints - of the game developer, the character, and the player - constructs the intended meaning for players.
\end{abstract}

Keywords: Liyla and the Shadows of War; (meta-)Ground Viewpoint Space; mobile game; multimodality; narrative; structurally-framed irony

\footnotetext{
*Corresponding author: Iksoo Kwon, Hankuk University of Foreign Studies, 107 Imun-ro, \#512 Faculty bldg., Dongdaemun-gu, 02450 Seoul, South Korea, E-mail: kwoniks@hufs.ac.kr

Eunsong Kim, Department of English Linguistics, Graduate School, Hankuk University of Foreign Studies, 107 Imun-ro, Dongdaemun-gu, 02450 Seoul, South Korea, E-mail: jenrya91@naver.com
} 


\section{Introduction}

A typical game - a category of which mobile games are an emerging member - is a competitive engagement in which players follow a set of rules to achieve a specific objective for the purpose of having fun. ${ }^{1}$ As electronic devices have entered daily life, so, too, have video games, including the adventure game, which is the specific kind of game this study is concerned with. In an adventure game, the player takes the role of the protagonist in a pre-programmed story, which is (more or less) fixed by the game developers. The player strives to clear all the game's given stages by overcoming obstacles and solving puzzles in the protagonist's journey. Mobile video adventure games are run by an app system, allowing a player to use a mobile device as a console to manipulate a protagonist in the story of the game. The purpose of such games is, in general, to advance and complete a predetermined final stage of a given quest. ${ }^{2}$ When the game story's protagonist achieves the main objective, the player who is paired with the protagonist wins the game, presumably leading to the player's satisfaction with what the protagonist has achieved in the mental space of the game story.

Adventure games, therefore, make outstanding sites to examine viewpoint phenomena, where multiple viewpoints at different conceptual levels interact with one another to construct emergent meanings (Dancygier 2012; Vandelanotte and Dancygier 2017). Such a game conveys the game developer's intended message via a series of images (non-verbal modality) and texts (verbal modality), and its meaning construction relies on multiple viewpoints invoked in the depiction of the framed event of the game story. The rules and the internal structure are designed by and thus subject to the creator's viewpoint. However, this structure is shared: players volunteer to take roles in the structure, and in these roles they engage in actions to try to outsmart their competitors; thus, the game is also subject to the viewpoints of the players and the characters whose roles they inhabit. The interaction among the multiple viewpoints embedded in any type of game becomes even more complicated in video games, which add another layer of narrative structure, wherein a narrator's viewpoint and a character's viewpoint are compressed, resulting in dynamic and emergent construals (as discussed in detail below).

1 This study uses the term 'mobile game' to refer to online platform software in which a player attempts to influence an outcome via a mobile device such as a smartphone or tablet. The study considers this kind of electronic game to be an example of an emerging member of the game category because it did not exist until the very recent rapid development of technology in mobile phones.

2 Section 2.1 discusses the adventure mobile game genre as literature. 
There is, however, a deviant example of an adventure game that does not end in the protagonist's achievement and the player's satisfaction: Liyla and the Shadows of War (Abueideh 2016). Inspired by true events of the 2014 Palestinian-Israeli conflict in Gaza, the game portrays the consequences of the conflict from the perspective of an unnamed Palestinian father who is struggling to escape the war zone with his daughter Liyla. The game's ostensible goal is to let the protagonists in the game survive and escape from the war zone to a safer place, but the players of the game are never able to complete the story in the expected way, no matter how skillful they are (see Section 2.1). This mismatch, and the irony ${ }^{3}$ it creates, makes the game a particularly interesting example of viewpoint phenomena.

This study presents a cognitive semantic analysis of the mobile game Liyla and the Shadows of War as a multimodal phenomenon of which the construal involves interaction of multiple viewpoints. The study focuses on how multiple viewpoints construct intended meanings for players. Specifically, this study argues that the multiple viewpoints involved form a network, rather than random clusters. For example, the player can access detailed background knowledge of the past real-world events that motivate the game's narrative structure, or information about how a mobile game operates, whereas the game character has no access to such knowledge regarding the narrative or the template. Further, the analysis shows how a sense of irony, specifically a kind of irony whose construal relies on genre expectations and thus is structurally framed, ${ }^{4}$ emerges from the game's deviation from prototypical games in which players are guided to complete an expected story by achieving given quests.

The study is concerned with the following research questions:

- How is it possible for the players to make sense of a generic real-world situation (i.e., human experiences in the Palestinian-Israeli conflict) out of the specific fictional narrative structure conjured up in the mobile game (i.e., a single person's journey through multiple types of tragic experiences)?

- How does the deviation of the structure of the game from the prototypical game structure affect the players' overall construal of the game?

- What generalizations can be drawn regarding the type of ironic construal found in this game?

3 This paper defines irony as 'a [cognitive] process whereby conceptual contents that are first construed subjectively are reconstrued as an object of conceptualization' (Tobin and Israel 2012: 44). Further details are provided in Section 4.2.

4 It is structurally framed because the game is structured and programmed by a narrative designed to not allow players to achieve the given quest. By subverting normal expectations regarding a mobile game template, this non-canonical structure contributes to the ironic construal, as discussed in more detail in Section 4. 
Section 2 provides background on the tragic incidents of war that motivated the mobile game and explains this study's theoretical tools. Section 3 addresses the research questions. First, Section 3.1 analyzes verbal and non-verbal expressions manifested in the game's plot, based on the theory of conceptual blending (Fauconnier and Turner 2002). To answer the second question, Section 3.2 explores the mismatch between the viewpoints of the player, the protagonist, and the developer of the game. Working within the framework of Viewpoint Spaces (Dancygier 2012), this study elaborates how gaps between these viewpoints are resolved, and elucidates how this resolution affects the player's overall construal of the game. In the elaboration, the notion of (meta-)Ground Viewpoint Space is proposed to account for a generalized global viewpoint space where local viewpoints construct the meanings in a network. Considering that approaches to viewpoint phenomena in terms of mental spaces are still in their infancy, this account is significant in demonstrating how the framework allows a transparent and elegant visualization of a construal. Lastly, regarding the third question, Section 4 discusses how the genre-based construal of irony can be generalized, briefly illustrating its argument with another instance of structurally-framed irony. Section 5 concludes the paper.

\section{Background}

This section provides information on the adventure mobile game in focus and the true story that the game is based on (Section 2.1), and describes the study's theoretical apparatus (Section 2.2).

\subsection{Liyla and the Shadows of War: The game and the true story}

Liyla and the Shadows of War is a mobile game in which a father takes a journey with his daughter to escape a war zone. It consists of three major components. First, a title page gives brief preliminary information about the game, explaining that it is based on actual events and suggesting the best way to play it (For best experience play this game in a dark room with headphones). The second component is the main narrative of the game, where a player controls the protagonist's decisions to take actions. Third, the end credits provide detailed information about the tragic events on which the narrative is based. For the main narrative, the game operates as a side-scrolling platformer: By using a smart phone as the game console, a player can control the father character's movement horizontally, moving the character to the left and right of the screen by touching arrows that appear on 


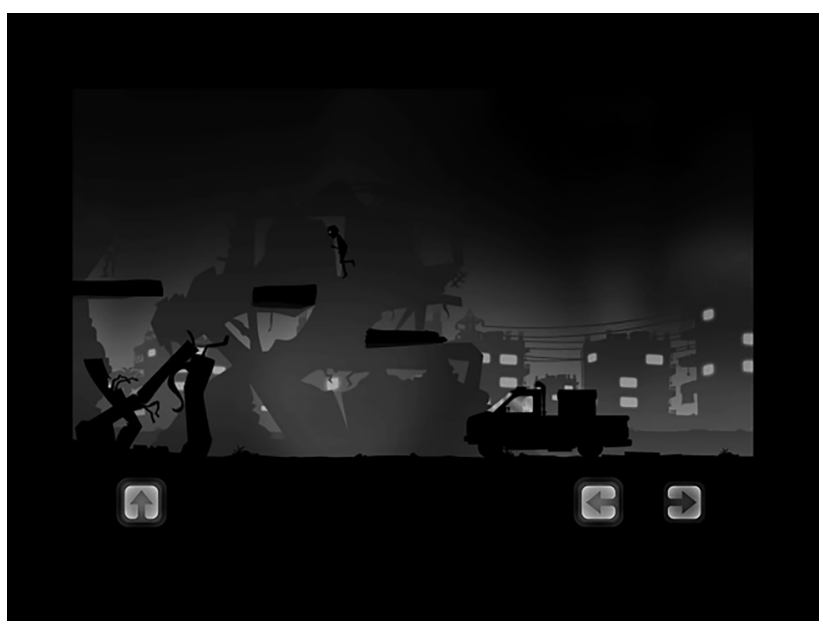

Figure 1: Side-scrolling platform.

the screen (Figure 1). Because the temporal backdrop of the narrative is nighttime, the palette is mostly grayscale, except for a few instances such as lights from bomb explosions, an ambulance light, destroyed buildings and ruins, and the time bar (in red, as shown in Figure 2).

The narrative includes three stages (bombing on a beach, bombing of a school, and bombing of an ambulance), each of which is inspired by a true event (details are provided in Section 3.1). The player progresses through the stages by accepting one of the choices that the game offers. For example, Figure 2 shows the challenge at the end of the second stage (the bombing of the school). In it, the character of

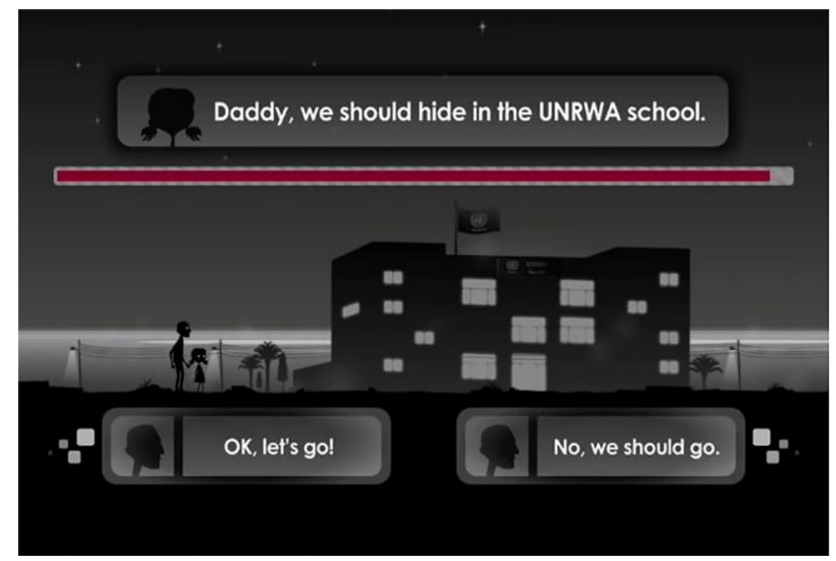

Figure 2: An example of a binary choice. 
Liyla says: Daddy, we should hide in the UNRWA school. The player, in the role of the father, must choose to respond: OK, let's go! or No, we should go. One of these answers (i.e., the answer that suits the game developer's narrative) allows the player to proceed to the next phase. After passing through the three stages as programmed (possibly through trial and error), end credits appear, revealing that the three stages are based on specific real events of the 2014 War on Gaza, along with numbers of casualties and destroyed facilities, as exemplified in Figures 3 and 4. The colours of the game, largely shades of gray and black with sporadically appearing red, strengthen the impression of danger. The soundtrack of the game is minimal, but includes sporadic mournful music (when the father and daughter have to leave her dead mother, and when end credits appear), and some sound effects that encode explosions or gunfire. ${ }^{5}$ The game takes about $15-20 \mathrm{~min}$ to play, and it operates in four languages: English, Spanish, Arabic, and Chinese.

What is special about Liyla and the Shadows of War is that the player needs to give an answer, regardless of whether it accords with his or her moral and/or commonsense beliefs, to clear all the stages. For instance, if the player answers the question given at the second stage with $O K$, let's go!, which seems to be commonsensical - assuming that civilian facilities such as a UN school would not be assaulted - the player will fail, and need to try it over again from the beginning of the stage. Moreover, if the player fails to make a choice within a given amount of time (a red bar indicates the time limit, as shown in Figure 2), the system automatically chooses the 'wrong' answer (the other two stages proceed in a similar way except that the last stage only gives one choice; see Section 3). Putting this in terms of viewpoints, the player's viewpoint is not synchronized with the game developer's, which leads to mixed feelings on the part of the player and evokes a sense of irony. In general, clearing all the stages of an adventure game is the desired goal to be achieved in as efficient a way as possible, but in this game, a player must sacrifice his or her moral and/or commonsensical beliefs to do so. This study argues that the sense of irony stemming from the three local stages of the game narrative constitutes a global sense of irony for the entire game. The ironic construal adds up as the programmed narrative runs against players' expectation for the frame invoked by the genre of mobile games (details are provided in Section 4). Little research has attempted to account for this emergent form of narrative (i.e., adventure mobile

5 While the visual and auditory choices involve intriguing symbolism and no doubt have cultural implications (Radden and Kövecses 1999: 20), this study merely assumes the game's colours and sounds were chosen to contribute to the ominous construal of the narrative, as the study's focus is limited to how the text and the schematic images yield emergent meanings. 
games), ${ }^{6}$ let alone its construal by means of cognitively motivated frameworks. This paper aims to fill this gap by accounting for the conceptual structure behind the construal within the framework of Viewpoint Spaces (Dancygier 2012). As a matter of fact, the presence of this meaning stratus in the game backs up Dancygier's claim that viewpointed meanings are constructed not randomly but in a systematic way, and, specifically, in a network.

The actual events that motivated Liyla and the Shadows of War can be recapitulated as follows. The 2014 Gaza conflict was a military clash between Israel and Palestine. ${ }^{7}$ The immediate cause of the war was the abduction and murder of three Israeli teenagers by Hamas on June 2014, though the feud between the two nations has been ongoing for decades. The conflict over the incident escalated to a fullfledged war when the Israel Defense Forces launched 'Operation Protective Edge' on July 8, resulting in the death of more than two thousand people until a ceasefire on August 26. Most of the casualties were Gaza residents; in addition to those who were killed or wounded, up to 500,000 Gazans were displaced because of the war. These facts are provided in the first scene of the game (as mentioned above) and in the end credits (as shown in Figures 3 and 4).

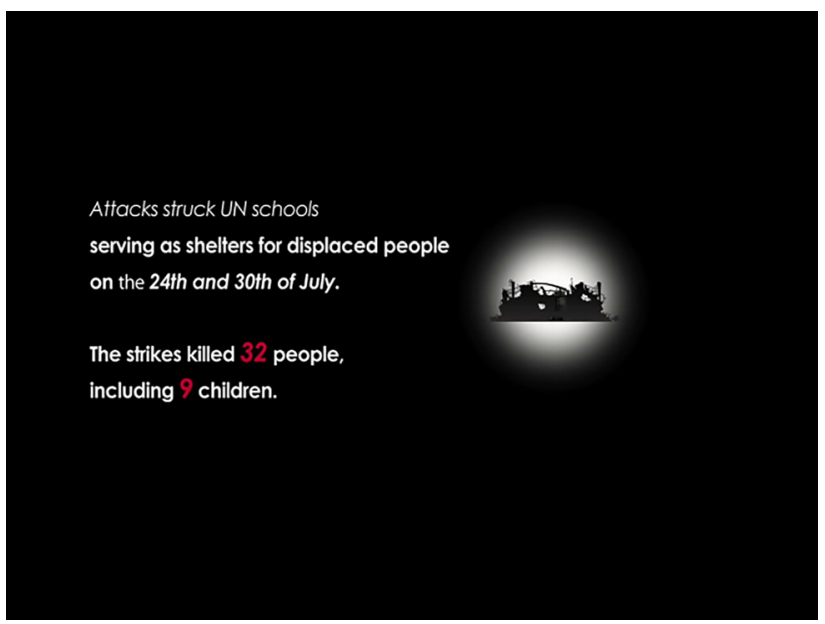

Figure 3: End credit - school bombing.

6 Kromhout and Forceville's (2013: 103) study is an exception. They mention that mobile games differ from typical literature despite similarities in structure (i.e., readers/viewers interpret what is encoded in a medium), because of the former's ergodicity. Ergodic literature requires a viewer (the player) to play an active role in empowering the text by manipulating a controller, unlike literature that is read.

7 https://www.independent.co.uk/news/world/middleeast/israel-gaza-conflict-50-day-war-bynumbers-9693310.html (Accessed on September 28, 2018). 


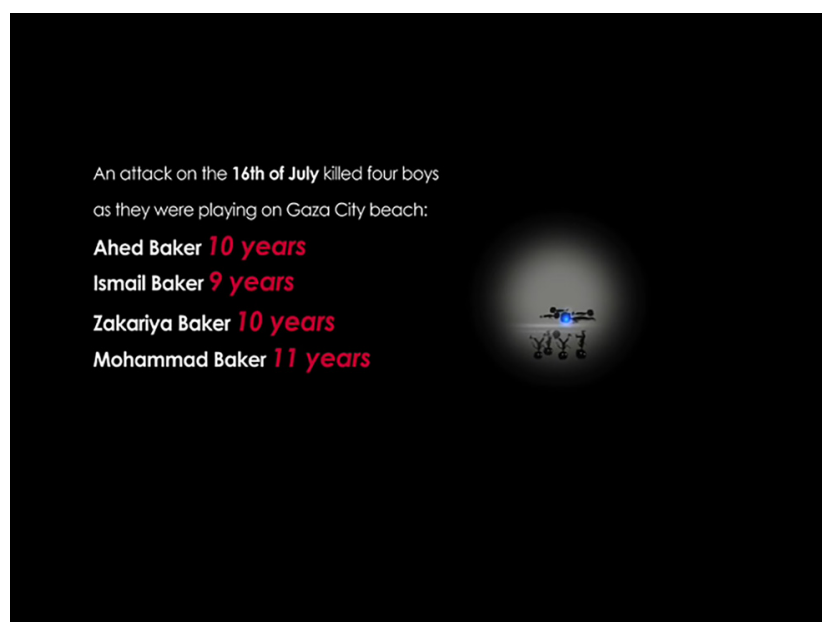

Figure 4: End credit - beach bombing.

The end credits of the mobile game Liyla and the Shadows of War $^{8}$ reveal that the story of the game is based on three actual events: (1) the bombing of children on a beach, (2) the bombing of the UNRWA (United Nations Relief and Works Agency for Palestine Refugees in the Near East) school, and (3) the bombing of an ambulance. In a process of abstraction and compression (see Sections 2.2 and 3.1), the game developer created the fictive characters, the father and the daughter in the story, to generically represent countless individual civilian victims of the war. Considering its ergodic nature, the story of the mobile game is being narrated and at the same time completed as the player makes choices for the protagonist in the given war situations. This schematic structure behind the narrative works to naturally invite players into the story and allow them to simulate it.

\subsection{Viewpoint compression and irony}

This section briefly discusses two important theoretical notions that function as a backdrop of the adventure mobile game and its narrative structure: compression (Fauconnier and Turner 2000) and viewpoint (Dancygier and Vandelanotte 2016, 2017a, 2017b; Vandelanotte and Dancygier 2017).

Compression is a cognitive mechanism that yields emergent meanings through conceptual blending (Fauconnier and Turner 2002). In conceptual blending, where contextually relevant semantic elements from two or more information packets

8 Press kit, http://liyla.org/press-kit. 
(i.e., mental spaces) become more salient than others, and where the selected elements complete a relevant event structure, new meanings emerge that otherwise would not have existed in any of the input information packets. As the relevant structure is formed, vital relations in the inputs are inherited by the blended structure, such as Cause-Effect, Time, Identity, and Intentionality. This process of inheritance necessarily involves compression, because semantic information from two or more input spaces must be made to fit in a single emergent event structure non-redundantly. For example, the actual events that motivated the mobile game Liyla and the Shadows of War involved different actors in reality, whereas the game's protagonist undergoes all three events in the game space, which indicates that the game space is the consequence of compression of selected elements from the real-world events.

Compression entails the existence of two or more mental spaces; therefore, the meanings that emerge from it naturally rely on interactions of multiple viewpoints. A mental space can be thought of as an information packet, which accommodates interlocutors' viewpoints as narratives or discourses unfold. Thus, mental spaces are constructed as humans think and talk, and these spaces can combine with each other to build up complex conceptual structures. Because it always presupposes the presence of cognizers, every constructed mental space inevitably involves viewpoint: the internal structure of a mental space is determined by frames and categories, not by disembodied logical operators, and they are necessarily viewpointed by an experiencing origo (Fillmore 2006 [1982]; Lakoff 1987).

The notion of viewpoint is far from being a new research topic, although most of the research has been conducted on focalization and speech and thought representation within narrative discourse (e.g., narratology, stylistics, poetics, etc.; Vandelanotte 2017:157). It is also worth pointing out, however, that this study differs from those in formal linguistics that concentrate on analyzing logophoric pronouns (i.e., a reflexive pronoun whose antecedent does not occur in the sentence itself; e.g., Cantrall 1974; Culy 1997) and related syntactic operations (Kuno 1987). Following an assumption of cognitive linguistics (Dancygier and Sweetser 2012; Dancygier and Vandelanotte 2017a, 2017b; Dancygier et al. 2016; Vandelanotte and Dancygier 2017), this study considers the notion of viewpoint to comprehensively describe any way of positioning or taking a stance toward a stimulus, including how one construes a stimulus (e.g., political perspective, emotional stance) and manners of indexical access (e.g., a vantage point from high ground, etc.). This study argues that a cognitively motivated theory accounts for the meaning construal of multimodal products with multiple viewpoints.

As a branch of Mental Spaces Theory (Fauconnier 1994, 1997), the framework of Viewpoint Spaces theory (Dancygier 2012) is useful to transparently account for meaning constructions out of interactions between discourse participants at different conceptual levels. That is, following Dancygier and Vandelanotte (2016), 
this study argues that viewpoints are hierarchically ordered and form networks, rather than being arbitrarily juxtaposed, and that this situation holds even in the construal of the narrative in an adventure mobile game. The construal of a narrative discourse generally requires that cognizers access multiple viewpoints (invoked in stance-taking forms of speech in regard to epistemicity, emotions, etc.), from which emergent meanings are constructed so that the cognizers interweave the meanings with their own viewpoints and further re-enact them in a network. To illustrate, Dancygier and Vandelanotte (2016: 15) offered the example in (1):

(1) Tomorrow was Monday. Monday, the beginning of another school-week! Another shameful, barren school-week, mere routine and mechanical activity (D. H. Lawrence, Women in Love, Ch. XV).

The narrator of the literary text in (1) has access to the character's emotional state from an omniscient perspective, and hence the viewpoints at the different conceptual levels interact with each other in the text. That is, the narrator (Current Speaker) portrays the character's (Represented Speaker's) negative impression of the first day of a school-week as uninteresting. Because tomorrow generally refers to the upcoming temporal cycle posterior to the deictic center, it would seem to be semantically contradictory to follow it with was. This temporal paradox is resolved

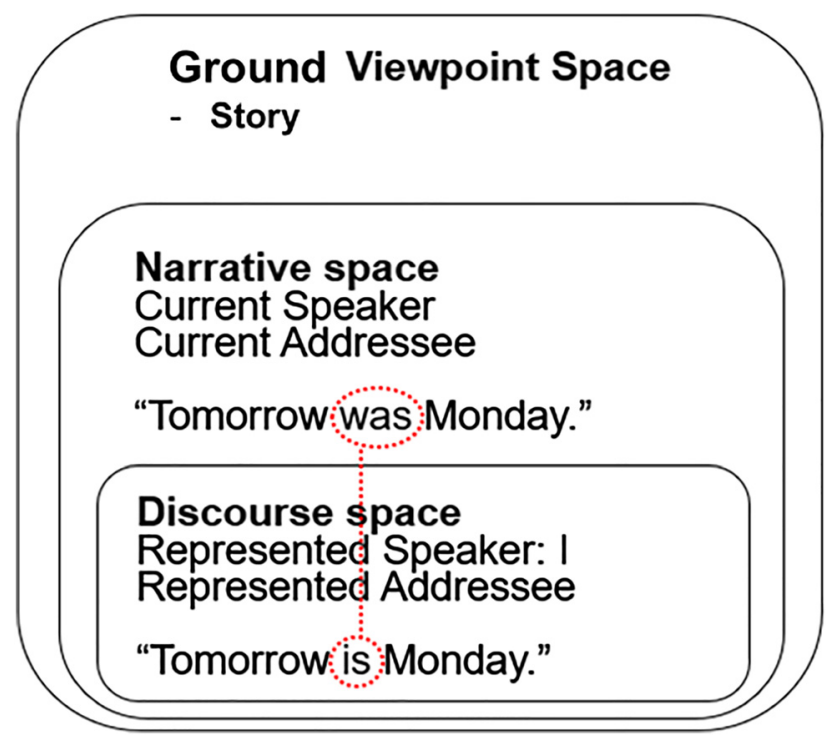

Figure 5: Viewpoint spaces network configuration of (1). 
in (1) because the two seemingly incompatible constructs are coherently accommodated in the higher space in the viewpoint spaces network, as shown in Figure 5.

The overall network contains at least three types of mental spaces: a discourse space, a narrative space, and the Ground Viewpoint Space (GVS) managing local viewpoints. Represented Speaker/Represented Addressee belong to a discourse space where the actual discourse Tomorrow is Monday takes place; Current Speaker/Current Addressee belong to a narrative space where the discourse space is re-framed from a narrator's (Current Speaker's) perspective. In the Ground Viewpoint Space, which is instantiated by a story, local viewpoint spaces are orchestrated, yielding the overall construal. Because the present event of the Represented Speaker is being narrated by the Current Speaker, the narrative space embeds the character's discourse space. The current interlocutors in the narrative space can access the represented interlocutors' internal experiences in the discourse space, but the represented interlocutors cannot access the story interlocutors' experiences. The dotted line illustrates the semantic relation that links the present tense in the discourse space to the past tense in the narrative space. The overall construal is obtained when information and viewpoints from all the local spaces are accessed appropriately from a bird's eye view, which is accommodated at the highest level of the network, GVS.

Notice that the layer of Ground Viewpoint Space is equivalent to Dancygier and her colleague's notion of Story/Discourse Viewpoint Space (Story Viewpoint Space, Dancygier 2012; Discourse Viewpoint Space, Dancygier and Vandelanotte 2016). This paper argues that the benefits of employing the alternative term are twofold. First of all, it provides a clearer indication of the bird's eye view in the network, which plays a crucial role in the multilayered meaning construction. Differing from Dancygier's assumption, as a matter of fact, a story oftentimes refers to a series of chronological events undergone by a protagonist (or character) before being narrated (equivalent to the notions of fabula [Bal 2009] and quest [Forceville 2011]), as opposed to a narrative where the chronological order may be reshuffled. ${ }^{9}$ In this respect, the term Ground Viewpoint Space helps avoid potential confusion. Second, the term broadens the scope of the theory, so that it is able to account not only for types of speech and thought representations or stories, but also for any linguistic/ multimodal signs prompting conceptual constructs and accumulating as the discourse progresses (Dancygier 2012: 36). Instead of using an instantiation of the Viewpoint Spaces network such as Story Viewpoint Space or Discourse Viewpoint

9 Throughout this paper, a narrative requires an (invoked) narrator and an (invoked) addressee, whereas a story does not. 
Space, it is more efficient to include the concept of ground to indicate a conceptual base where multiple viewpoints at different levels coherently interact and hence construct optimal meanings in the given context. ${ }^{10}$

In a similar way, the game Liyla and the Shadows of War allows different interpretations. It has at least two strata: one stratum where the game character graphically represented in the game (i.e., a represented participant) is on a journey to take his daughter (i.e., another represented participant) to safety; and another stratum where the game developer (i.e., the current speaker) narrates the father's story to the player (i.e., the current addressee). These two strata form a hierarchical network of viewpoints, with the following entailment: the current interlocutors of the story are aware of the represented interlocutors (the characters of the father, daughter, etc.) and the events in which they are involved, whereas the represented interlocutors are not aware of the current interlocutors. In addition, the mixed feelings the game may evoke in the players can be accounted for by the different purposes of the two strata. The purpose of the first stratum is the purpose of the represented interlocutor (the father): to save his daughter by taking her to a safer place through acting on the basis of morality and commonsense. In contrast, the purpose of the second stratum is that of the current addressee: to clear the game's stages, and thus to 'win', regardless of morality and commonsense.

This paper proposes the notion of Ground Viewpoint Space, a top-level space in the viewpoint networks of communicative artefacts including mobile games, which supervises local viewpoint spaces and regulates the construal of a given stimulus based on simultaneous access to local viewpoints. Within the network, interlocutors can freely access other narrative viewpoint spaces beyond temporal and spatial constraints. The paper also contends that the presence of a Global Viewpoint Space facilitates an ironic construal as a cognizer's realization of the invoked meta-mental space gives rise to re-evaluation of given information (further discussed in Section 4). The network is formed based on interlocutors' intersubjective meaning negotiations via conceptual compression of multiple viewpoints. This study aims to support the claim that meanings are constructed in a viewpoint network by conducting a case study on a novel form

10 This paper argues further that the presence of a Global Viewpoint Space reveals a cognitive basis behind the construal of multilayered viewpoint constructions including literary texts, internet memes (Dancygier and Vandelanotte 2017b), political posters (Roh et al. 2019), etc. Their construals commonly involve multiple viewpoints at different conceptual levels: those at a level that are reframed at a higher level, and those doing the reframing at the higher level. The hierarchical network of viewpoint spaces yields an emergent construal that is obtained from a bird's eye view by accessing the local information packages simultaneously. Further details are discussed in Section 4. 
of narrative, the adventure mobile game, within the Viewpoint Spaces framework (Dancygier 2012).

\section{Data analyses}

This section first describes the compression of multiple separate events into the single journey of a single protagonist in the mobile game's narrative (Section 3.1). It then models conceptual structures for the construal of the game's three stages and of the game's overall sense of irony (Section 3.2).

\subsection{Compression}

As briefly described in Section 2.1, the story that the current speaker (i.e., the game developer; CS, henceforth) conveys to the current addressee (i.e., the game player; $\mathrm{CA}$, henceforth) is a reconstruction based on a series of actual events (a fact that is clearly explained in the epilogue of the game). The screenshots of the game in Figures 6-9 represent four real events in which civilians were subjected to assault. Figure 6 portrays the usage of white phosphorus shells by Israel; ${ }^{11}$ Figure 7 represents the death of four Palestinian boys who were playing on a beach;; ${ }^{12}$ Figure 8 depicts the demolition of a UN school in an Israeli assault, which killed civilians

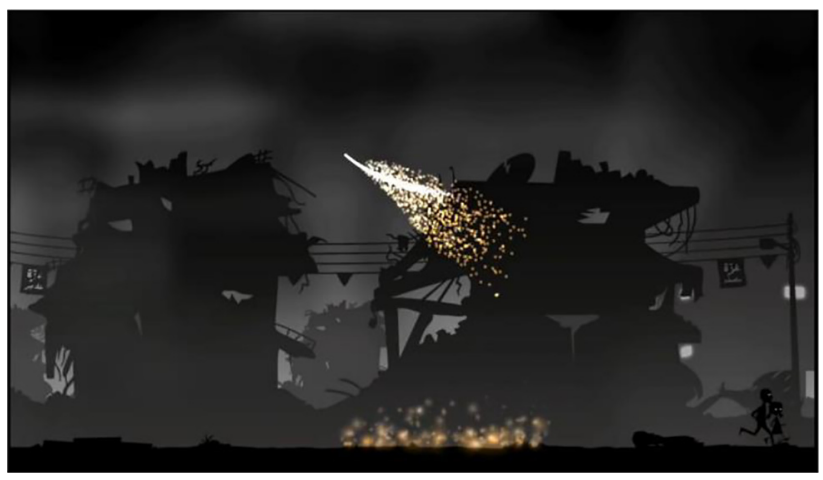

Figure 6: White phosphorus bombs.

11 https://www.hrw.org/news/2009/03/25/israel-white-phosphorus-use-evidence-war-crimes (Accessed on July 24, 2018).

12 https://www.nytimes.com/2014/07/17/world/middleeast/gaza-strip-beach-explosion-killschildren.html (Accessed on July 21, 2018). 


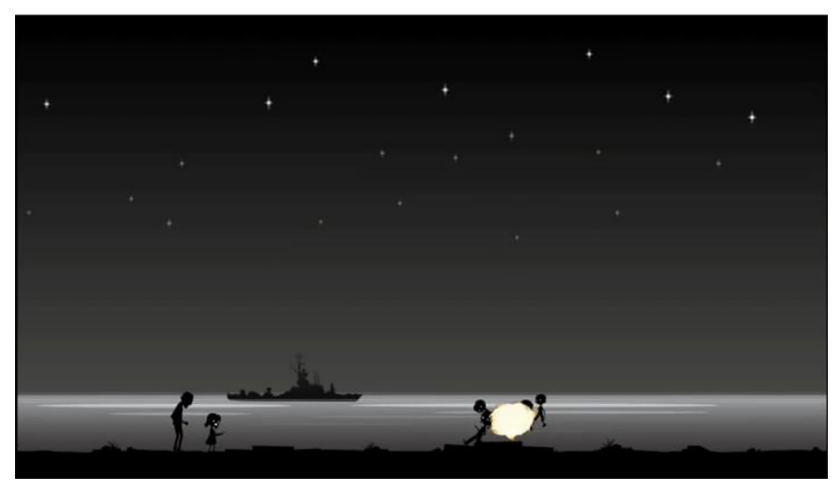

Figure 7: Battleship attacking children.

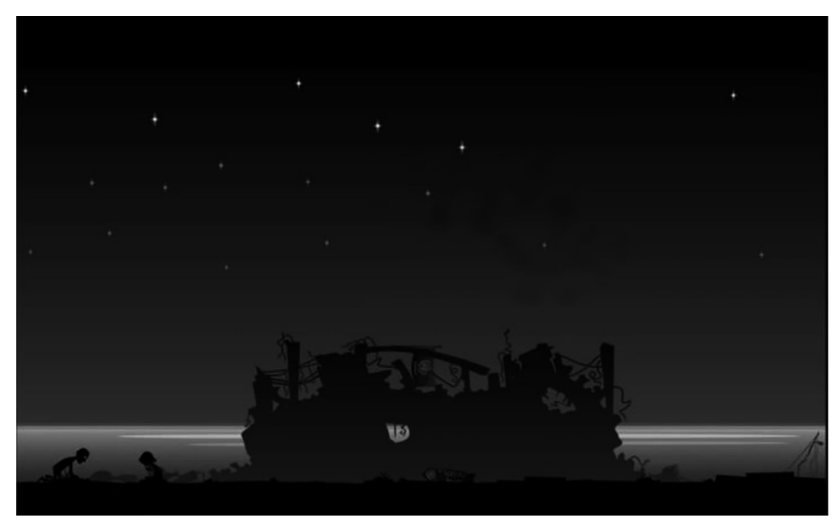

Figure 8: Bombed UNRWA school.

who were taking shelter inside; ${ }^{13}$ Figure 9 shows a bombed ambulance with a civilian holding the body of his daughter, who was killed in the blast. ${ }^{14}$ Each of these events occurred at different times and places in reality; thus, the story as it unfolds in the game is a consequence of compression of the four input events into a single event, which is modeled in Figure 10.

In Figure 10, each of the input spaces accommodates relevant pieces of information for each of these events, all of which have the same event structure, in which an agonist undergoes a change of state due to an antagonist's exertion of

13 https://www.theguardian.com/world/2014/aug/08/-sp-gaza-israeli-strikes-unrwa-schools (Accessed on July 23, 2018).

14 https://www.theguardian.com/commentisfree/2015/jun/29/2014-conflict-gaza-healthcarehospitals-war-crime-israel-hamas (Accessed on July 24, 2018). 


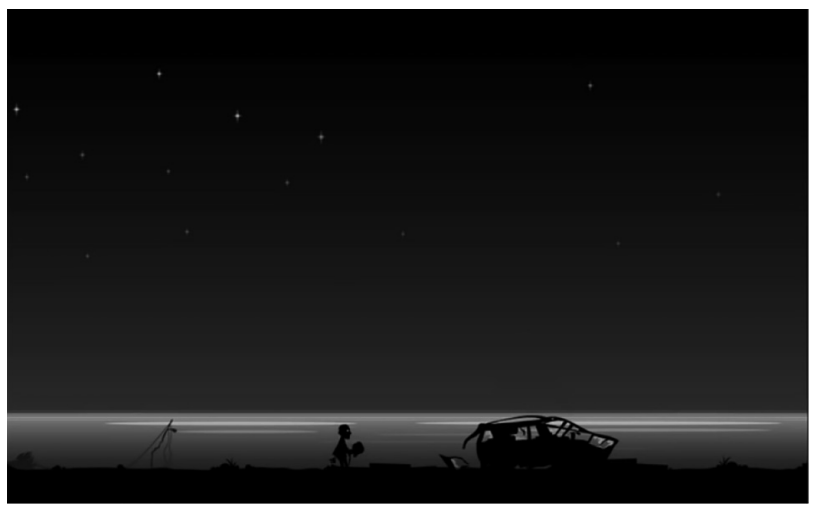

Figure 9: Destroyed ambulance.

force. ${ }^{15}$ The detailed values of each input space differ; for example, the time in Input 1 (2008-2009) versus Inputs 2-4 (2014), and the precise locations ( $x, y, z$, and $w$ ) of each event. Further, the identities of the specific agonists, although they were all Palestinian civilians $(c, d, e$, and $f)$, and specific antagonists, although they were all Israeli military $(i, j, k$, and $l$ ), differ. The world that appears in the game is a consequence of the compression of these values (time, place, identity of agonist and antagonist) into a single coherent fictive but motivated blended space in which all the tragic events are experienced by one civilian, $\mathrm{C}$ (with his daughter), in an overnight journey.

Intriguingly, the result of compressing individual events into a single event is an emergent construal of duration; it takes about 15 min to play the whole game, which would not make sense in the individual input spaces. In addition, in the real-world spaces of any one of the inputs, subsequent assaults following immediately after the current assault would not be expected; nor do the genericized agonist (C, Liyla's father) and antagonist (I, the Israeli forces) exist in the inputs. This abstraction process makes it possible for a player to accept the story as it unfolds in the game whether or not the player has specific knowledge of the Gaza conflict. The inferential patterns obtained from the interplay between the inputs and the blended spaces suggest that both compression and backward projection (Fauconnier 2005: 531) play crucial roles in the construal of the network. Backward projection consolidates the construal by grounding the input knowledge when the end credits reveal that the inputs are factual and give the details of the real-world events (e.g., numbers of casualties, names of the victims, etc.). The moment

15 An agonist is a force-dynamic term that refers to any entity that an external force is exerted upon; the source of the external force is the antagonist (Talmy 2000). 


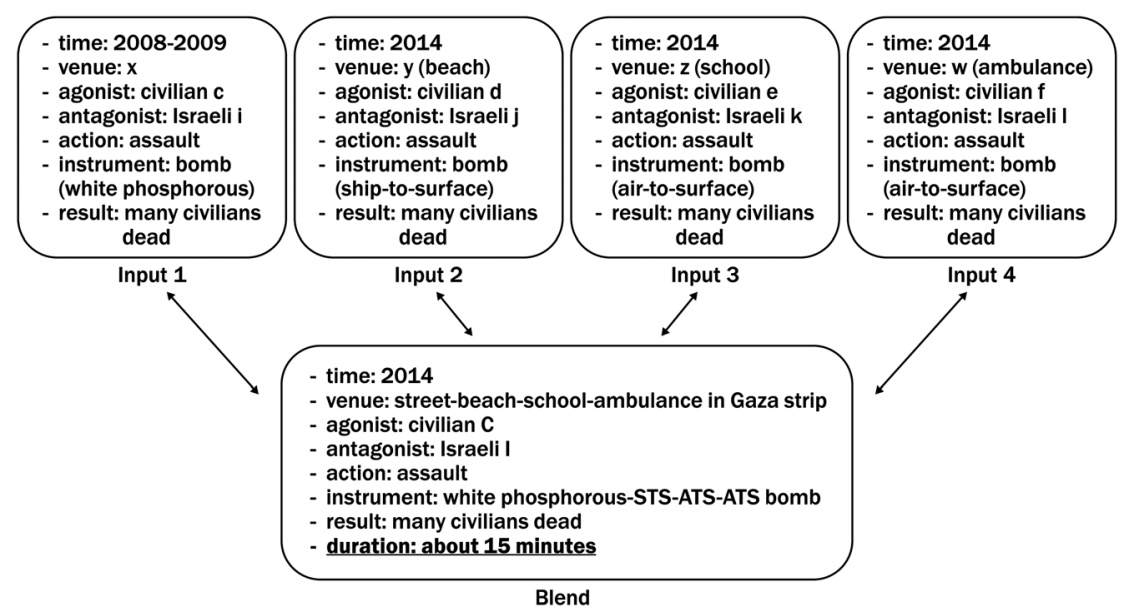

Figure 10: Compression in the conceptual integration network involved in the game. ${ }^{16}$

cognizers realize that the narrative embedded in the game is not fictive but based on true events, via backward projection, the cognizers' feelings of uneasiness, guilt, and helplessness will be strengthened because the narrative is no longer some imaginary event; the narrative becomes the cognizer's reality.

\subsection{Viewpoints}

This section first provides detailed analyses of the three stages of the game's narrative in terms of Viewpoint Spaces networks, and then considers the overall construal of the whole game, focusing on the sense of irony.

To begin with, Figure 11 portrays a first stage scene in which Liyla and the represented interlocutor (i.e., the father; RI, henceforth), as they are fleeing from a white phosphorus attack, come across children playing football on a beach.

The message box at the top of the screen shows what the other RI (Liyla) says; she is asking permission to tell the children to join them in their escape. By pressing one of the boxes below, the player can decide whether to let Liyla approach the other children or to ignore them. Both of the choices have consequences: if the player attempts to take the children along, a battleship will appear and launch a missile onto the beach, killing Liyla and the other children; ${ }^{17}$ if the player decides to leave instead, Liyla will survive, but the beach will still be bombed and the other children will die. The player feels uncomfortable either way, in that there is nothing that he or she can due to save the children on the beach. The

17 This choice leads to the 'game over' screen, at which point the game starts again. 


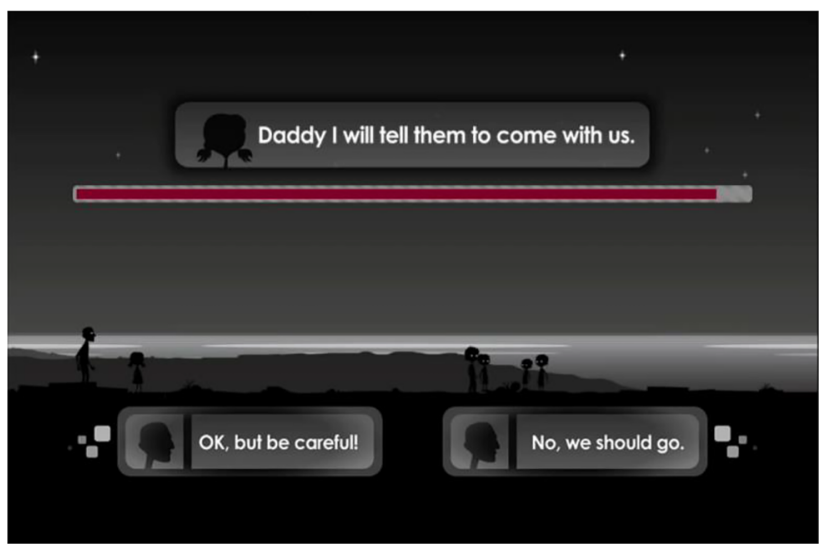

Figure 11: The beach bombing scene.

player's discomfort will only increase as she or he realizes the game designer's intention; that is, to continue to play the game, a player, in the role of the RI, must continue to try to gain safety for his/her own family, even if that requires making immoral decisions such as not trying to save others' lives.

To fully grasp the conceptual structure of the construal of this scene, this study models the multilevel viewpoint network for each of the scenarios. There are at least three possibilities for how the player, in the role of RI, can proceed: (1) to choose to let his daughter warn the other children, (2) to choose to walk away from the other children with his daughter, or (3) to choose (1) and then (2). ${ }^{18}$ Figure 12 is a representation of the construal process for scenario (1), in which the player chooses to let Liyla warn the children only to witness her death. Note that a narrative space in general represents an event structure in which a current speaker (e.g., a game developer) conveys a story to a current addressee (e.g., a player). Note also that a discourse space represents a story; it contains the represented speakers, and the space constructs meaning together with other spaces (e.g., the spaces of shared beliefs or other relevant information packets). For example, in Figure 12, a cognizer in the Narrative Space can access the Discourse Space, the Belief Space of morality, and the Expectation Space regarding how to play a mobile game.

By making a choice of $O K$, but be careful, the player must witness the character's failure to fulfill the mission of saving Liyla. Thus, the game obtains the overall construal that a moral decision at war may result in an undesirable consequence. The Discourse Space (DS) accommodates a story portrayed in the game, represented by the verbal dialogue between Liyla and her father. The Belief Space comes into the

18 How players tend to actually make choices in the game is briefly described in Section 4. 


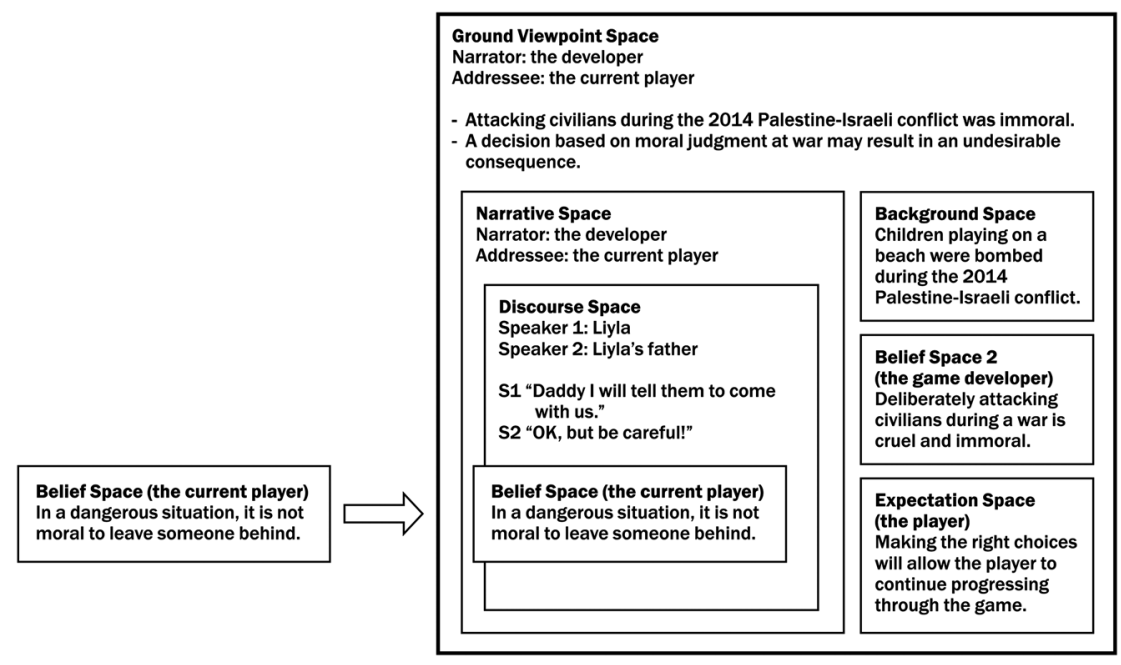

Figure 12: Viewpoint network when $O K$, but be careful! is chosen.

Ground Viewpoint Space (GVS), and stretches between the Narrative Space (NS) and DS, indicating that the player in the NS and the father character in the NS's subordinate DS share the commonsense belief of the real world that it is not moral to leave someone behind in a dangerous situation such as war, as the father character is an avatar under the player's control. ${ }^{19}$ Because the game itself is based on a real event, the Background Space contains information about that event. The second belief space in focus (Belief Space 2) also contributes to the overall interpretation, as the game developer intends to emphasize that deliberate attacks against civilians are immoral. The Expectation Space accommodates the player's expectation that making the right choice during the gameplay will allow him or her to clear the current stage and proceed to the next one. Notice, however, that the meaning of being right can be contested. From a game player's perspective, a choice is procedurally right or wrong in terms of its effect on the game and regardless of its morality; from a humanitarian perspective, a choice is morally right or wrong regardless of its real-world or game-world effect. A player who assumes that a morally right choice is the procedurally right choice within the game will press the $O K$, but be careful! button, expecting this action to be a satisfactorily right choice from both

19 What is represented by the Belief Spaces in the figure is concerned only with kinds of belief that are closely related to the construal in focus. There are many backgrounded beliefs in this context; for instance, that playing outside during a war is not safe; that civilians are not targeted by military forces, etc. This study assumes that this variety of background beliefs is implied in the Base Space of the Viewpoint Spaces network. 
perspectives. It is present in the model because it plays a crucial role in yielding the mixed feeling of discomfort due to its incongruity with moral belief. The overall construal is obtained only when a cognizer simultaneously accesses all the aforementioned spaces from the GVS in the network. This entails that the GVS is where a cognizer can see all of the local information contained in it, as if he or she has a bird's-eye view, so that he or she can attend to relevant elements by zooming in and out in the mental space and picking up the best-fitting construal of the given context (Tobin and Israel 2012; see also Section 4). The fact that the cognizer's viewpoint is anchored to the GVS is indicated by profiling the outer layer (marked with a thicker line) in the figure (Langacker 1990). ${ }^{20}$

For the player who presses the $O K$, but be careful! button, after Liyla and the other children get killed by the blast, the 'game over' screen is shown and the program forces a restart from the initial phase. Upon perceiving the gap between his/her expectation and reality, the player's attention zooms out to the higher-level Ground Viewpoint Space, where the incongruity can be resolved by accessing, through hindsight, the game developer's intention, which is not construed until the player accesses the GVS. To describe the same process in terms of mental spaces, zooming out from the DS (the story of the game) to the GVS (where the cognizer is aware of both the game narrative and the story in it) via the NS (the narrative), the player comes to realize the CS's (game designer's) intention. This intention, which resides outside the story, is to convey that a decision based on moral judgement in a wartime situation can have a bad consequence. The construal at this point can lead to another try with the second choice: No, we should go; the player has realized that a moral choice will not let the protagonist proceed to the next stage (thanks to the Expectation Space), and he or she has to go through the alternative scenario to proceed.

Figure 13 models the conceptual structure involved in the construal for the second choice. Notice that the player in Figure 13 is assumed to not have gone through the first choice; he or she has no knowledge of what happens if the first option is chosen. Because the protagonist here chooses to leave the children behind, a belief that prioritizes survival over morality must be at work; this time, the player believes it is better to put one's own safety first than to take risks by helping others, and this belief is aligned with the father character.

To choose No, we should go consequently allows the player to proceed to the next stage, which might solidify the player's belief that prioritizing one's or one's family's own security is 'right' in wartime. This result might nevertheless lead to another mixed feeling of accomplishment and of guilt, as the result that is desirable from the game player's perspective cannot be achieved without the choice

20 Profiling refers to how linguistic expressions highlight particular parts of the conceptual structures they refer to (Langacker 1990: 5). 
that is inexcusable from the humanitarian's perspective. Compared to Figure 12, the representation in Figure 13 differs only in that the information accommodated by the belief space is more about survival than about morality.

The last scenario is that the player makes the first choice, faces the consequence, and tries again with the second choice. The conceptual structure involved in this scenario is represented in Figure 14. Compared to Figure 13, the conceptual structure is similar in that the DS contains the same represented dialogue between Represented Speaker 1 (Liyla) and Represented Speaker 2 (her father). The Expectation Space, however, contains different information, which is obtained and accumulated from the player's mistake of choosing the first option at the beginning: leaving the children behind will let the player proceed to the next stage, but, presumably, requires the player to act against his or her moral beliefs. As the cognizer (i.e., the player) accesses the local spaces within the GVS simultaneously, the best-fit construal emerges that war victims are forced to make choices against morality in order to survive, and if they do survive, they have to live on with a sense of guilt. This is the construal the CS (i.e., the game developer) would like players to have after having invited them to play and simulating the traumatic experiences of civilian victims of war. The sense of irony stemming from the mismatch between the two viewpoints is the key to this construal, and this section accounts for the construal process by representing the cognizer's dynamic and flexible access to the relevant pieces of information in the Viewpoint Spaces network.

The same kind of challenge or dilemma is intentionally presented to the player at each stage of the game, and this study contends that it is these dilemmas and forced

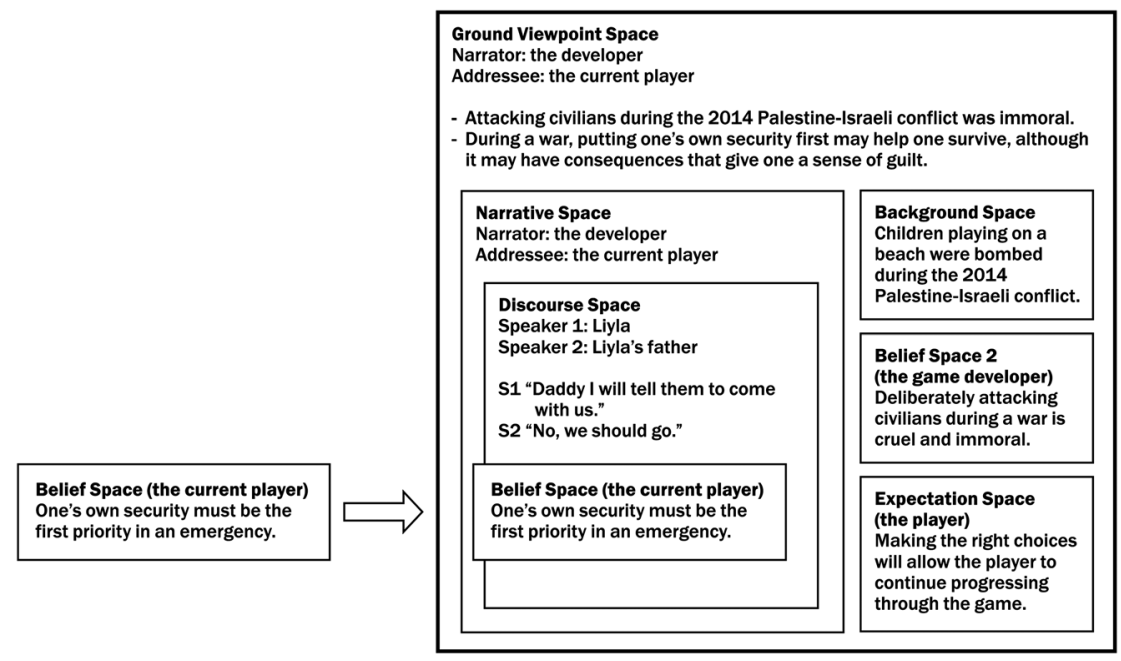

Figure 13: Viewpoint network when No, we should go is chosen. 


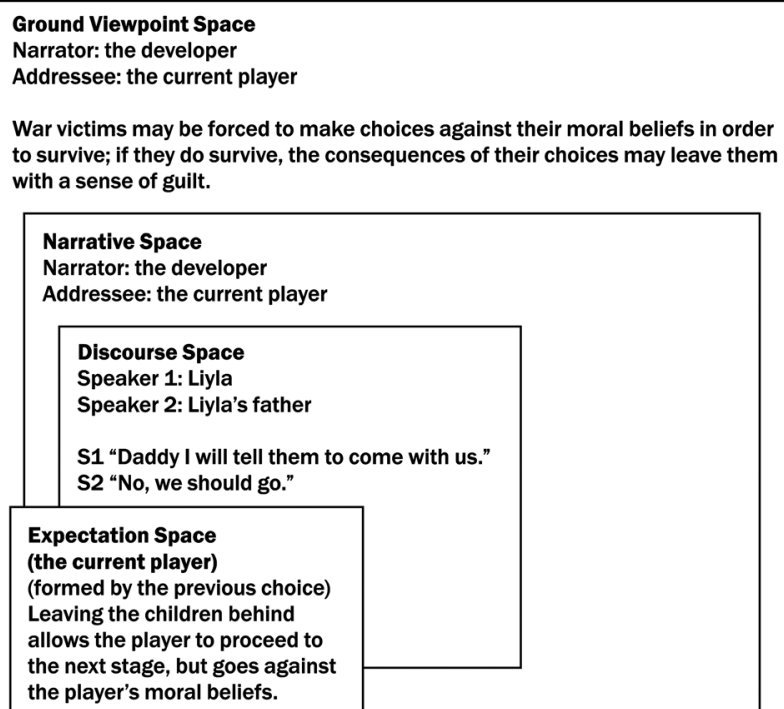

Figure 14: Viewpoint network for the final interpretation of the beach bombing scene.

choices that consolidate the overall meaning constructed throughout the whole game, which is to cast light on the traumatizing and horrendous aspects of war.

The second stage is portrayed in Figure 15, in which Liyla and her father consider taking shelter at the UN school after having survived the beach bombing.

In the given scene, RS1 (Liyla) tells RS2 that they should hide in the school. Now, the CA (the player) has to choose between OK, let's go! and No, we should go. The player's first choice is likely to be the former, based on the assumption that the school, as a civilian facility established by the UN, would provide shelter and be safer than staying outside in a war zone. If this choice is made, however, it turns out that the school is bombed, the represented characters in the story die, and this stage of the game starts over again. If the player chooses the latter, the school is still bombed, but the represented characters survive, although they get injured in the blast from the bombing. The default and pre-programmed response is to hide in the school, which automatically results in failure.

The conceptual structure involved in the construal of the scene can be represented as in Figure 16. Specifically, the figure represents when the player chooses the first option (entering the school) only to witness the represented characters die, which yields the construal of criticism of the Israeli assaults on civilians during the 2014 Gaza conflict. Notice that the Belief Space is brought in and stretches between DS and NS, similarly to the case represented in Figure 12 above, as both the RI and 


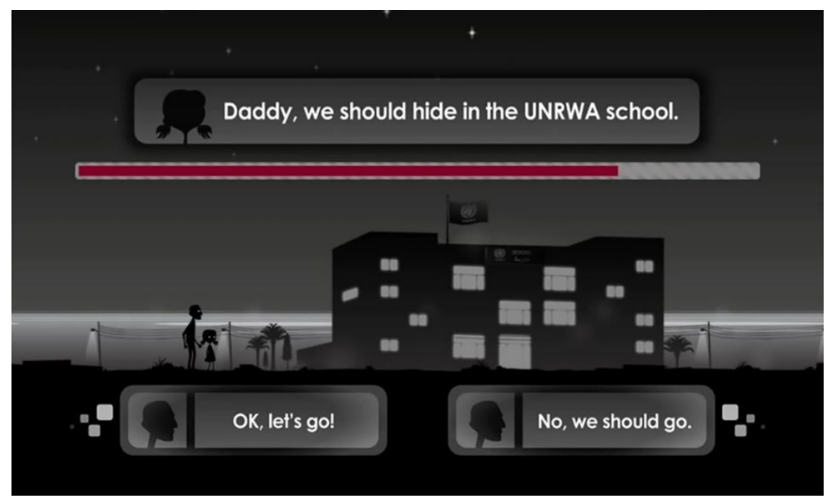

Figure 15: The UNRWA school bombing scene.

the CA are presumed to share a commonsense belief that going into a civilian shelter would be safer than staying outside in a war zone. Also notice that the Background Space accommodates information on the 2014 Gaza conflict, which provides a backdrop for the overall construal with a specific relation to the actual event that occurred in the past.

At this stage, again, there are three possibilities for the player's response to the challenge: (1) to choose OK, let's go! which results in failure, (2) to choose No, we should go and proceed to the next stage, and (3) to choose (1) and then (2); that is, to go through a process of trial-and-error and proceed to the next stage, a process that adds to the sense of irony being constructed in the game. The player eventually obtains the construal that common sense does not hold during wartime, that the Israeli bombing attack against civilians is immoral, and that, nevertheless, to clear this stage, he or she needs to sacrifice common sense. The conceptual structure of the trial-and-error process is schematically identical to that of the first stage (the beach bombing scene), differing from it only in that the Belief Space has a commonsensical (Figure 16) rather than a moral basis (Figure 12). The bird's-eye view in the GVS gives the player access to the actual event of the 2014 Gaza conflict, which leads to the player obtaining the ironic construal as he or she recognizes that the consequence of choice (1) does not conform to the commonsensical expectation. The cognizer has simultaneous access to the locally activated mental spaces, and as he or she zooms out, the maximal viewing frame (profiled, and marked by the thicker line in the figure) yields the ironic construal.

It is noteworthy that another kind of expectation is compromised when the player does manage to clear the second stage. That is, upon choosing the second option, the represented characters are injured by the blast, which goes against an expectation created by the first stage that sacrificing one's beliefs will allow the 
characters to survive the scene safely. This incrementally worsening story leads to the last stage - the ambulance bombing scene. After the school bombing scene, Liyla and the protagonist keep walking until they find an ambulance waiting for patients. Figure 17 illustrates this scene with the dialogue, in which the paramedic tells Liyla's father, The ambulance is full. I can only take one patient. This time, the player is not given two choices; there is a single button to click: I have no option, please take my daughter. As soon as the player takes this action, a bomber appears in the sky and drops a missile onto the ambulance, which is completely destroyed, and Liyla is killed. This leads to the final scene, in which her father picks up Liyla's body, and her soul rises up into heaven to reunite with the soul of her dead mother. Then, the end credits appear with the information on the victims of these terrible real-life incidents.

The fact that the player is given only one choice evokes the helpless frustration that one might feel as a war victim. Even though the 'right' choice has been made in the given situation, the player is destined to fail. Further, the situation of the third stage is worse than that of the previous stages in that no other alternative is available and no further action is possible. This structural constraint contributes to the emergent sense of irony because games generally entail the player's expectation that making the 'right' choice allows one to proceed. The moment this incongruity is acknowledged, the ironic sense is maximized in association with the discomfort that comes from witnessing the failure. Again, the game's ability to evoke this complicated mixture of feelings can be accounted for only if there is a systematic hierarchy of viewpoint spaces that enables a cognizer to

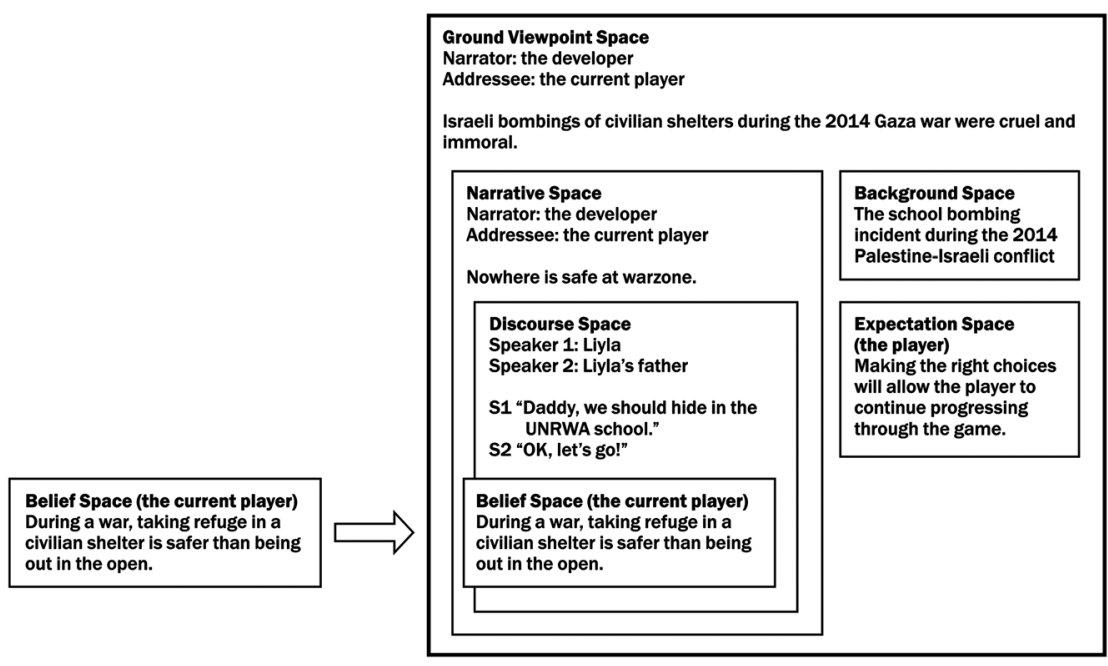

Figure 16: Viewpoint network for the UNRWA school bombing scene. 


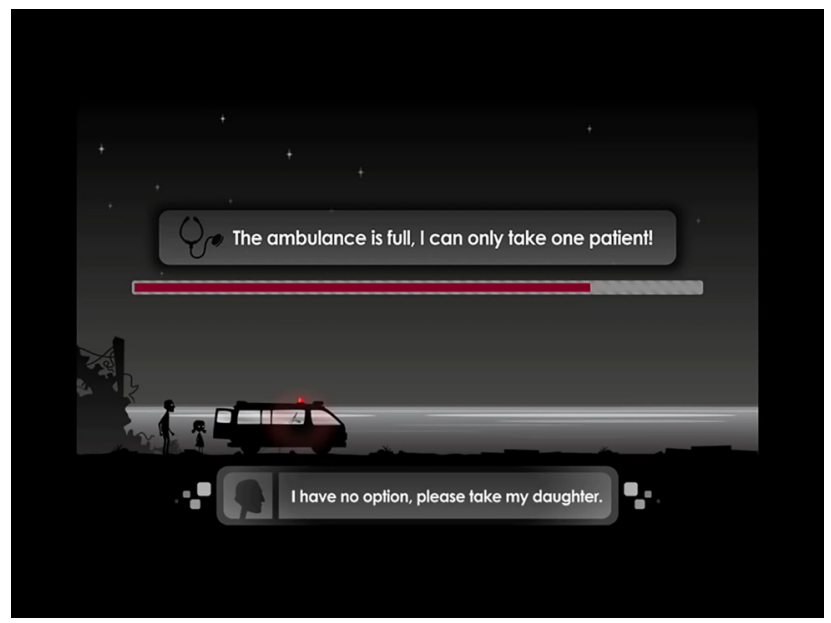

Figure 17: The ambulance bombing scene.

simultaneously access the multiple event structures accommodated in multiple mental spaces. The conceptual structure involved in the construal can be modeled as in Figure 18.

Figure 18 represents the viewpoint network of the game's third stage as a series of two phases. In the first phase of the conceptual structure (Discourse Space, Phase I in the figure), the choice has been made automatically; the second phase (Event Space, Phase II in the figure) shows its consequence. The conversation between the paramedic and Liyla's father that takes place in the first phase is likely to evoke a commonsensical belief that a wounded person will be safe once in a paramedic's hands. In the second phase, however, this belief space is violated by the consequence: the ambulance is destroyed and the child dies. These two consecutive phases are concerned with the focal story narrated by the game. When a cognizer accesses the multiple spaces simultaneously, including the Background Space, Belief Spaces, and Expectation Spaces, he/she obtains the meanings of the cruelty of war and the helplessness of war's victims. Note that what the Expectation Space implies is even stronger than in the two previous stages: the player would expect to be given a binary question (Expectation Space 2), as in the previous stages. The defiance of this expectation by the scene in question would sharpen the sense of helplessness as it echoes civilian victims' complete lack of choice during a war. As the player perceives that there is no escape and that the situation is hopeless, he or she also realizes that this is precisely the intention of the game.

It is important to note that after the player has passed through all three stages, the game automatically projects the numbers of casualties and of destroyed 


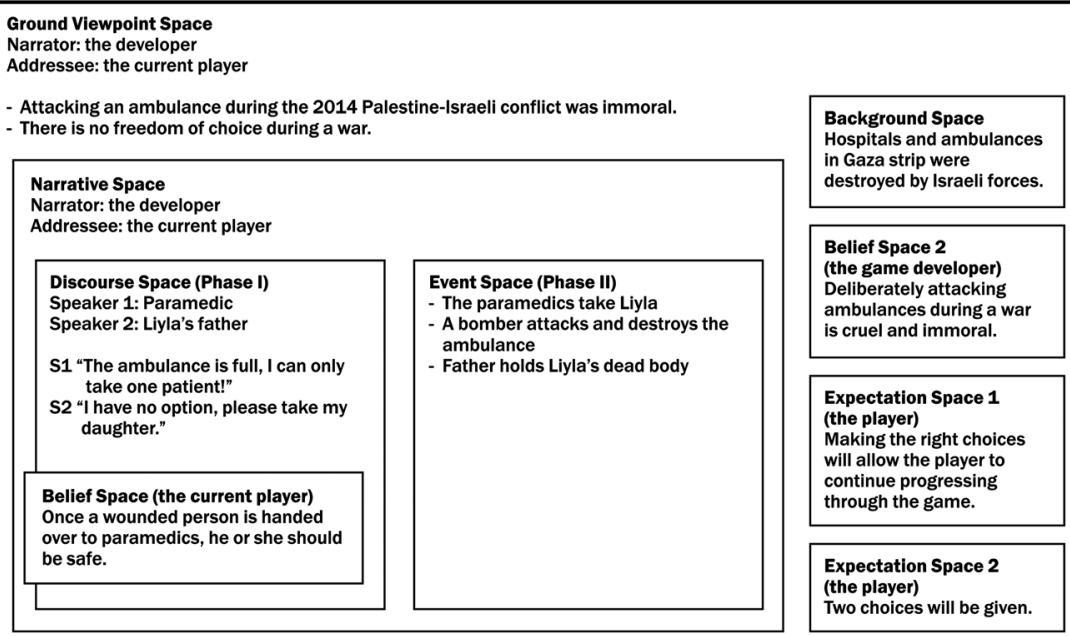

Figure 18: Viewpoint network for the ambulance bombing scene.

buildings in the 2014 Gaza conflict by means of text. When this background knowledge comes into play, the player now realizes that the whole game was inspired by the actual events of war in the 2014 Gaza conflict.

\section{Discussion: Structurally-framed irony}

As this study has shown, the overall construal of the mobile game Liyla and the Shadows of War relies on irony. More specifically, as the locally constructed mental spaces accommodating depicted situations in the game and the real-world background information evoked by these depictions are viewed in terms of Viewpoint Spaces networks, the cognizer accesses multiple mental spaces and recognizes an invoked higher space. Then, he or she reframes (and sometimes compromises) the relevant entailments and inferences of his or her expectations, and in this way obtains the emergent ironic meanings.

Before full discussion of this specific type of irony, this study provides an attested account of how people actually construe irony from this game. A survey was conducted of participants who had played the game. A total of 66 English Linguistics students at a Korean university (59 undergraduates, seven graduates) participated for extra course credit. The survey asked them to (1) specify in what sequence they made selections regarding the given questions in the three stages, and (2) write a short description (at least 50 Korean characters, not counting 
spaces) of how they felt after finishing the game, including the end credits. The first question gave the following four choices, with the results in Table 1.

A. First stage: fail $\rightarrow$ start over $\rightarrow$ first stage: pass $\rightarrow$ second stage: fail $\rightarrow$ start over $\rightarrow$ second stage: pass $\rightarrow$ third stage \& end

B. First stage: fail $\rightarrow$ start over $\rightarrow$ first stage: pass $\rightarrow$ second stage: pass $\rightarrow$ third stage \& end

C. First stage: pass $\rightarrow$ second stage: fail $\rightarrow$ start over $\rightarrow$ second stage: pass $\rightarrow$ third stage \& end

D. First stage: pass $\rightarrow$ second stage: pass $\rightarrow$ third stage $\&$ end

As shown in the table, most of the participants chose the order of (D), and the fewest chose the order of (A). Put differently, 45.5\% of the respondents chose the character's survival over a moral and/or commonsensical course of action at every stage of the game. Only five respondents experienced failures in all the stages and had to start over, and the rest went against their moral judgment at least once for the purpose of clearing the given stages, that is, winning the game.

Answers to the second question revealed the respondents' reasoning behind their choices. Twenty respondents (just under a third) seemed to feel the game differed from a normal one, using words such as counter-expectation, helpless,

Table 1: Number of answers per choice for the first question in the survey.

\begin{tabular}{lrrrrrr}
\hline Choice & A & B & C & D & Total \\
\hline Answers & $5(7.6 \%)$ & $18(27.3 \%)$ & $13(19.7 \%)$ & $30(45.5 \%)$ & 66 \\
\hline
\end{tabular}

cruel, clear message, guilty feeling, and so forth. One of the respondents who played in the order of (D) answered to the second question that '[E]very time I just skipped to do some actions and just kept going and ignoring, I was able to survive. But, at the same time, I thought that would not be the end and there would be other dangerous situations ahead of me. At last, I came to have no other choices. And I felt helpless.' The respondent wanted to clear all the stages and so ignored all the given moral challenges on purpose, believing that it would be the only way for the character to survive the game. It eventually made them feel unsafe and helpless, as the game character's daughter dies in one way or another in the narrative. Although the majority did not follow the order of choices in (A), which would reflect the greatest adherence to moral/commonsense choices, the results indicate that the participants were well aware that the game itself had nothing to do with reality, that the priority of a game is to clear all of its stages by any means, and that they nevertheless felt guilty because of the choices they had to make to complete the game. In other words, they felt a sense of accomplishment but also a sense of moral failure, which, this paper contends, is the source of the ironic construal intended by the game developer. 


\subsection{Irony: Exhuming an invoked higher mental space}

What this paper means by irony refers to any communicative act and/or artefact that accompanies a cognitive process whereby conceptual contents that are first construed subjectively are reconstrued as an object of conceptualization (Tobin and Israel 2012: 44). By this definition, irony may broadly include sarcasm and humor, whose construal also requires cognizers to simultaneously access multiple layers of information of what is encoded and what is implied. At any rate, the phenomenon of irony as well as other phenomena that have been regarded as adjacent to irony can be explicated in a uniform way (Tobin and Israel 2012: 31): irony can be defined as a result of a process in which a focused proposition is accessed and viewed; it is a way of construing an expressed proposition as a shift takes place in a cognizer's attention from an inner mental space to an outer layer in the space network, which is indicated by profiling outer layers in this study. As a consequence of this shift, the cognizer gains access to a dynamic blended construal of an event from multiple viewpoints, and this is the core of how an ironic sense is constructed.

For example, the utterance Thanks for holding the door conveys an ironic meaning when a person preceding the speaker through a doorway does not in fact hold the door for the speaker (Kihara 2005: 514). The sense of irony arises only when the cognizer accesses both the real-world situation, in which the speaker castigates the person ahead for not holding the door, and the fictive expectation situation, in which the very same utterance would be used to express appreciation for the courteous gesture of holding the door. Switching to the cognitive semantic terminology, the sense of irony is obtained as the cognizer realizes the implicit presence of an invoked situational frame and thus accesses both mental spaces accommodating what has really happened and mental spaces accommodating what is expected to happen. The presence of a higher space is needed for cognizers to conceptually accommodate both types of mental space, to construe the incongruity, and to obtain the ironic construal stemming from the incongruity. The incongruity is flexibly construed depending on how the incongruity is framed; in an identical situation, another ironic utterance, Thanks for shutting the door (Kihara 2005: 514), is perfectly fine, even though the truth conditions denoted by holding and shutting are quite different.

The same kind of process is found in the conceptual structure of the mobile game's narrative, considering that it involves the cognizer's simultaneous access to multiple spaces for each of the stages. Furthermore, the GVS networks of the three stages are embedded in an even higher level, which we call meta-GVS, where the cognizer accesses all the relevant information revolving around the three depicted incidents simultaneously, which eventually yields the ironic sense at this 
highest layer of the network, paired with the game developer's intention to make anyone who plays this game feel hopeless and helpless. The conceptual structure of this kind of structurally-framed irony is illustrated in Figure 19.

In Figure 19, GVS 1, 2, and 3 represent the construals of the three stages - the beach bombing, the UNRWA bombing, and the ambulance bombing. These three local spaces are accommodated within a profiled meta-space, which allows the cognizer to zoom out and access the information evoked by the three stages simultaneously. The construals of irony obtained at each of the local layers, GVS 1, 2 , and 3, constitute a grounded sense of irony, which is the overall construal of the mobile game that the player obtains at the end of the game's narrative. That is, once those who play through the game perceive that, unlike in other mobile games, it is not they but the game developer who controls the process of the game, they will also perceive the helplessness and hopelessness that are the consequences of war.

After the end credits of the game reveal that it is based on real incidents of the Gaza conflict (see Figures 3 and 4 in Section 2.1), the construals of each local GVS resonate with this background information. As they access the background information that is explicitly unveiled by the images (represented by background spaces evoked by the end credits in Figure 19) from the meta-GVS, cognizers recognize that the narratives framed in each GVS are not fictional, and reconstrue the meta-narrative via backward projection such that the seemingly fictive narratives are grounded by the attested information about the victims. As this explicit information appears in the end credits, it becomes the salient information at the moment and contributes to the overall construal, which is represented by the profiled background spaces in Figure 19. The separate construals of the specific

Meta-GVS

Narrator: the developer

Addressee: the current player

The 2014 Palestinian-Israeli conflict was cruel and unjust for the civilian victims in Gaza

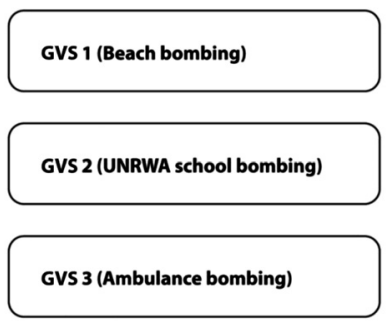

Background Space 1

(Beach bombing)

Background Space 2

(UNRWA school bombing)

Background Space 3

(Ambulance bombing)

Figure 19: The overall construal of the game Liyla and the Shadows of War. 
events thus stack up to evoke the cruelty and immorality of war in general. The player eventually obtains the following interpretation: the 2014 Palestinian-Israeli conflict was cruel and unjust for the civilian victims in Gaza. This interpretation arises naturally from the mismatch between the different viewpoints of the different layers: the goal of the player is to clear every stage of the game and to reach its end, whereas the developer's goal is to convey a message to the player. The structurally-framed irony of the game emerges because no matter how the player reaches the end of the game, the protagonist of the game's story fails in his quest. Most importantly, it is ironic because traumatic real-world war experiences are turned into a matter of winning or losing in a game.

\subsection{Structurally-framed irony: The presence of meta-Ground Viewpoint Space}

What is structurally-framed irony, exactly? In general, an ironic construal involves a conflict between different viewpoints - inner voices - on a given situation: the way one views the given situation comes to clash with the way it is apparently viewed by another. In this respect, realization of an invoked frame facilitates the construal of irony, because it identifies a hidden layer of mental space as well as an explicit layer. The moment a cognizer recognizes the presence of the implicitly invoked frame, he or she simultaneously accesses both of the viewpoints, which are incongruous with each other, and obtains the construal of irony.

What this study means by structurally-framed irony is a type of ironic construal where an implicit viewpoint invoked, particularly by genre, conflicts with another viewpoint looking on a given ostensible situation in the cognizer's mind, as in the case of the mobile game we have been discussing. There is an extensive range of other possible examples, as many diverse genres and their relevant stereotypical knowledge can be invoked as frames. In a video game, as discussed, players would normally achieve expected goals at the end of its narrative; in a hero novel/movie, protagonists would overcome difficulties, conquer villains, save victims, and so on. A bumper sticker reading Welcome to Berkeley - Here is your Bumper Sticker is subject to a structurally-framed ironic construal when viewers access the invoked frame knowledge regarding a specific genre of communicative artefacts, American bumper stickers that convey the car owner's political and/or ideological opinions. Thus, the Berkeley sticker suggests: 'no matter what your political opinion may be, once you are in Berkeley (which is famous for free speech and individuals' expression of their political opinions), you need to have a bumper sticker; even if you do not have an opinion, you can have a bumper sticker like this, a vacuous one'. 
A paper by Horace Miner (1956) presents another outstanding example. Apparently an academic journal article of the kind in which authors normally report a scientific study in a sincere and objective way, and make meaningful generalizations based on observed phenomena, the paper takes an anthropological fieldworker's perspective, introducing the seemingly exotic culture of a community called Nacirema:

[P]rofessor Linton first brought the ritual of the Nacirema to the attention of anthropologists twenty years ago ... but the culture of this people is still very poorly understood. They are a North American group living in the territory between the Canadian Cree, the Yaqui and Tarahumare of Mexico, and the Carib and Arawak of the Antilles.... According to Nacirema mythology, their nation was originated by a culture hero, Notgnihsaw, who is otherwise known for two great feats of strength ... (p. 503)

It goes on to report several examples of exotic cultural rituals such as the following:

[T] he latipso ceremonies are so harsh that it is phenomenal that a fair proportion of the really sick natives who enter the temple ever recover. Small children whose indoctrination is still incomplete have been known to resist attempts to take them to the temple because 'that is where you go to die'. Despite this fact, sick adults are not only willing but eager to undergo the protracted ritual purification, if they can afford to do so ... (p. 505)

The short paper ostensibly reports new findings in a clearly organized way as it concludes, based on the review of their exotic rituals, that the ritual life of the Nacirema indicates that they are a magic-ridden people.

The reader realizes, however, that the research paper is structurally-framed irony once he or she gets the anagrams Nacirema (America), Notgnihsaw (Washington), and latipso (hospital), thus piercing the disguise of pedantry invoked by the genre - an anthropological academic journal article. Common sense tells us that an author of an academic paper in anthropology would sincerely report in just such a pedantic way the details of what they believe are new discoveries. The very sincerity and pedantry invoked by the genre contribute to the ironic construal: the way anthropological fieldwork studies people keeps readers from realizing that what is being scrutinized is actually themselves.

Switching to Viewpoint Spaces terms, the anthropological fieldworker's ostensible observation gets reframed and re-evaluated in a higher invoked space. This resolution of different viewpoints entails that the cognizer obtains simultaneous access to both of the viewpoints from the meta-GVS that accommodates them all, including the frame knowledge of the genre itself (i.e., an academic research paper). The presence of the meta-GVS accounts for multilayered meaning 
constructions such as various types of irony, and specifically constructions whose construal relies on genre-related background knowledge.

\section{Conclusion}

This study has provided a cognitive semantic analysis of the mobile game Liyla and the Shadows of War as a viewpoint phenomenon whose construal necessarily involves the interaction of multiple viewpoints encoded or evoked by the text and graphics of the game. The study modeled how multiple viewpoints construct the intended meanings for players by accounting for the conceptual structures involved in the scenes of the game within the Viewpoint Spaces framework (Dancygier and Vandelanotte 2016). More specifically, the study examined verbal and non-verbal expressions manifested in the game's plot and special effects by drawing on the theory of conceptual blending (e.g., compression over time and space; Fauconnier and Turner 2002). The paper proposed the notion of Ground Viewpoint Space as a cover term for a global mental space where local spaces and viewpoints relate to one another and yield an emergent construal. This generalized notion can be instantiated by various kinds of communicative forms: discourse, stories, and so forth. In addition, by pointing out the effects of the mismatch between the viewpoints of the player, the protagonist, and the developer of the game, the study argued that the game's ironic construal is the result of meaning negotiation based on this mismatch. In the case of Liyla and the Shadows of War, in contrast to other adventure mobile games, the goal of the game developer is to make the players witness the protagonist failing in his quest. The study showed how the ironic construal was constructed at the highest level of the viewpoint network as well as at the local layers by modeling the networks within the framework of Viewpoint Spaces. Specifically, the newly proposed notion of metaGround Viewpoint Space provides a way to elaborate how the mismatch of viewpoints is resolved in the network, and to elucidate the significant meaning contribution of the invoked genre-specific expectation to the player's overall ironic construal of the game.

Acknowledgment: This study was supported by Hankuk University of Foreign Studies Research Fund; This study was supported by Department of Education of Republic of Korea and Korea Research Foundation (NRF-2018S1A5A8026846). 


\section{References}

Bal, Mieke. 2009. Narratology: Introduction to the theory of narrative. Toronto: University of Toronto Press, Sch.

Cantrall, William R. 1974. Viewpoint, reflexives, and the nature of noun phrases. Berlin: De Gruyter Mouton.

Culy, Christopher. 1997. Logophoric pronouns and point of view. Linguistics 35(5). 845-859.

Dancygier, Barbara. 2012. The language of stories: A cognitive approach. Cambridge: Cambridge University Press.

Dancygier, Barbara \& Eve Sweetser (eds.). 2012. Viewpoint in language: A multimodal perspective. Cambridge: Cambridge University Press.

Dancygier, Barbara \& Lieven Vandelanotte. 2016. Discourse viewpoint as network. In Barbara Dancygier, Wei-lun Lu \& Arie Verhagen (eds.), Viewpoint and the fabric of meaning: Form and use of viewpoint tools across languages and modalities, 13-40. Berlin: De Gruyter Mouton.

Dancygier, Barbara \& Lieven Vandelanotte. 2017a. Image-schematic scaffolding in textual and visual artefacts. Journal of Pragmatics 122. 91-106.

Dancygier, Barbara \& Lieven Vandelanotte. 2017b. Internet memes as multimodal constructions. Cognitive Linguistics 28(3). 565-598.

Dancygier, Barbara, Wei-lun Lu \& Arie Verhagen (eds.). 2016. Viewpoint and the fabric of meaning: Form and use of viewpoint tools across languages and modalities. Berlin: De Gruyter Mouton.

Fauconnier, Gilles. 1994. Mental spaces: Aspects of meaning construction in natural language. Cambridge: Cambridge University Press.

Fauconnier, Gilles. 1997. Mappings in thought and language. Cambridge: Cambridge University Press.

Fauconnier, Gilles. 2005. Compression and emergent structure. Language and Linguistics 6(4). 523-538.

Fauconnier, Gilles \& Mark Turner. 2000. Compression and global insight. Cognitive Linguistics 11(3). 283-304.

Fauconnier, Gilles \& Mark Turner. 2002. The way we think: Conceptual blending and the mind's hidden complexities. New York: Basic Books.

Fillmore, Charles. 2006 [1982]. Frame semantics. In Dirk Geeraerts (ed.), Cognitive linguistics: Basic readings, 373-400. Berlin/New York: Mouton de Gruyter.

Forceville, Charles. 2011. The journey metaphor and the source-path-goal schema in Agnès Varda's autobiographical gleaning documentaries. In Monika Fludernik (ed.), Beyond cognitive metaphor theory: Perspectives on literary metaphor, 281-297. London: Routledge.

Kihara, Yoshihiko. 2005. The mental space structure of verbal irony. Cognitive Linguistics 16(3). 513-530.

Kromhout, Roelf \& Charles Forceville. 2013. LIFE IS A JOURNEY: The source-path-goal schema in the videogames half-life, heavy rain, and grim fandango. Metaphor and the Social World 3(1). 100-116.

Kuno, Susumu. 1987. Functional syntax. Chicago: University of Chicago Press.

Lakoff, George. 1987. Women, fire, and dangerous things: What categories reveal about the mind. Chicago: University of Chicago Press.

Langacker, Ronald W. 1990. Subjectification. Cognitive Linguistics 1(1). 5-38.

Miner, Horace. 1956. Body ritual among the Nacirema. American Anthropologist 58(3). 503-507. 
Radden, Günter \& Zoltán Kövecses. 1999. Towards a theory of metonymy. In Klaus-Uwe Panther \& Günter Radden (eds.), Metonymy in language and thought, 17-59. Amsterdam: John Benjamins Publishing Company.

Roh, Jung Hwi, Wooyong Jin, Eunsong Kim, Hayoung Kim \& Iksoo Kwon. 2019. Multimodality and discourse viewpoint configuration: A case study of UK political posters. Linguistic Research 36(2). 289-323.

Rohrer, Tim. 2005. Mimesis, artistic inspiration and the blends we live by. Journal of Pragmatics 37. 1686-1716.

Sweetser, Eve \& Gilles Fauconnier. 1996. Cognitive links and domains: Basic aspects of mental space theory. In Gilles Fauconnier \& Eve Sweetser (eds.), Spaces, worlds, and grammar, 1-28. Chicago/London: University of Chicago Press.

Talmy, Leonard. 2000. Toward a cognitive semantics, Volume 1: Concept structuring systems. Cambridge, MA: MIT Press.

Tobin, Vera \& Michael Israel. 2012. Irony as a viewpoint phenomenon. In Barbara Dancygier \& Eve Sweetser (eds.), Viewpoint in language: A multimodal perspective, 25-46. Cambridge: Cambridge University Press.

Vandelanotte, Lieven. 2017. Viewpoint. In Barbara Dancygier (ed.), The Cambridge handbook of cognitive linguistics, 157-171. Cambridge: Cambridge University Press.

Vandelanotte, Lieven, \& Barbara Dancygier. 2017. Multimodal artefacts and the texture of viewpoint. Journal of Pragmatics 122. 1-9.

\section{Data}

Abueideh, Rasheed. 2016. Liyla and the Shadows of War. Nablus. Android OS. https://play. google.com/store/apps/details?id=org.liyla.war\&hl=ko. iOS. https://itunes.apple.com/kr/ app/liyla-and-the-shadows-of-war/id1100839270?mt=8 (accessed 27 July 2018). 